\title{
A ESCRITA NA UNIVERSIDADE: DIFICULDADES NA REDAÇÃO DO VESTIBULAR E PERSPECTIVAS PARA ALUNOS DO CURSO DE DIREITO
}

\section{WRITING AT UNIVERSITY: DIFFICULTIES IN THE VESTIBULAR ESSAYS AND PERSPECTIVES FOR LAW COURSE STUDENT}

Sueli Cristina Marquesi*

Pontifícia Universidade Católica de São Paulo, São Paulo, SP, Brasil

Ana Lúcia Tinoco Cabral**

Universidade Cruzeiro do Sul, São Paulo, SP, Brasil

Resumo: Neste artigo, refletimos sobre dificuldades de escrita de alunos ingressantes de uma universidade brasileira. A partir dos dados levantados em resultados de vestibular para curso de Direito e da análise de uma redação, propomos reflexões que orientam 0 trabalho de escrita na universidade, com vistas à superação das referidas dificuldades. Os procedimentos analíticos que adotamos conjugam noç̃oes de plano de texto (ADAM, 2011) e de contexto (VAN DIJK, 2012; 2016), bem como estudos sobre revisão de escrita (PINTO, 2015; HEURLEY, 2006). Para a discussão, recorremos a uma redação retirada de corpus constituído por redaç̦es de um processo seletivo de 2017 para 0 curso de Direito.

Palavras-chave: Escrita; Ensino na universidade; Plano de texto; Contexto; Revis̃̃o..

Abstract: In this article, we reflect upon the incoming students' writing difficulties from a Brazilian university. From the data collected in the vestibular results for the Law course and an essay analysis, we propose reflections that guide the work of writing in the university, with a view to overcoming these difficulties. The analytical procedures that we adopt combine notions of text plan (ADAM, 2011) and context (VAN DIJK, 2012; 2016), as well as studies on writing review (PINTO, 2015; HEURLEY, 2006). For the discussion, we use an essay drawn from a corpus consisting of texts produced during 2017 admission selection process to the Law course..

Keywords: Writing; University Teaching; Text Plan; Context; Review.

* Professora doutora da Pontifícia Universidade Católica de São Paulo - PUC-SP, São Paulo, SP, Brasil; suelimarquesi.sm@gmail.com

* Professora doutora da Universidade Cruzeiro do Sul - UNICSUL, São Paulo, SP, Brasil; altinococabral@gmail.com 
Linha D'Água (Online), São Paulo, v. 31, n. 1, p. 51-71, jan.-abril 2018

\section{Introdução}

Exames que atestam os conhecimentos dos estudantes ao finalizarem o ensino médio constituem instrumentos que lhes chancelam o ingresso no ensino universitário. Tais exames incluem, além de questões que aferem o domínio do conteúdo estudado ao longo da vida escolar, uma prova de redação, por meio da qual se avalia o nível de competência escritora do aspirante ao ensino superior. Assim acontece no Exame Nacional do Ensino Médio (Enem) e nos exames vestibulares.

No que diz respeito à produção escrita, a divulgação de resultados do Enem e de muitos exames vestibulares tem evidenciado que os textos dos estudantes que ingressam na universidade deixam muito a desejar em relação ao esperado. Diante dessa constatação, estabelecemos duas perguntas:

O que revelam os critérios para avaliação de redações de vestibular e os resultados da correção em relação às habilidades de escrita dos ingressantes no ensino superior?

Que estratégias podem ser utilizadas para superar as dificuldades de escrita dos ingressantes no ensino superior, futuros profissionais?

Considerando nossos interesses de pesquisa no campo do Direito (MARQUESI, 2014; MARQUESI, 2016; MARQUESI; RODRIGUES; CABRAL, 2016; CABRAL, 2015; CABRAL; MARQUESI, 2015), focalizamos nossas reflexões nessa área do ensino universitário. Assim, o material analisado compõe-se dos critérios de avaliação de redações, de um conjunto de redações provenientes de vestibular para o curso de Direito e dos resultados da correção dessas produções realizada pelos avaliadores.

De modo a responder às duas questões elencadas, estabelecemos quatro objetivos: 1. verificar os critérios estabelecidos para a correção dos textos, de modo a analisar o que eles indicam no que diz respeito aos processos de produção escrita; 2. analisar os resultados obtidos por um conjunto provas de redação de candidatos ao curso de Direito; 3. verificar o que esses resultados indicam em relação ao nível de habilidade escrita dos ingressantes; 4. refletir sobre estratégias que possam propiciar o aprimoramento da produção escrita de alunos de cursos de Direito.

Para dar conta dos objetivos traçados e responder às perguntas explicitadas, este texto está organizado em quatro partes, além desta Introdução, da Conclusão 
Linha D'Água (Online), São Paulo, v. 31, n. 1, p. 51-71, jan.-abril 2018

e das Referências. Na primeira parte, apresentamos algumas questões teóricas sobre a escrita e abordamos, entre outros aspectos, os conceitos de contexto, de plano de texto e de revisão; na segunda, apresentamos os parâmetros estabelecidos pela proposta de redação do vestibular, os critérios para a correção dos textos e os resultados apurados em uma amostragem de 50 provas, o que nos permite apresentar algumas reflexões em torno das condições de escrita; na terceira, analisamos uma redação do vestibular de Direito (Anexo); na quarta, retomamos e articulamos as partes precedentes, de modo a refletir acerca de estratégias que possam auxiliar no aprimoramento da escrita de estudantes de Direito.

\section{0 processo de produção escrita: contexto, plano de texto e revisão}

Conforme definem Marquesi, Elias e Cabral (2017, p. 14), texto é "uma construção organizada de forma estrutural, cuja finalidade é cumprir propósitos comunicativos”. A concepção proposta pelas autoras vai ao encontro dos postulados de Koch (1997), para quem o texto é uma manifestação verbal constituída de elementos linguísticos selecionados e ordenados pelos falantes durante a atividade verbal, de modo a permitir aos parceiros, na interação, não apenas a depreensão de conteúdos semânticos, em decorrência da ativação de processos e estratégias de ordem cognitiva, como também a interação (ou atuação) de acordo com práticas socioculturais (KOCH, 1997, p. 22).

Da definição de Koch, ressalta-se o aspecto social, prático, que permeia o texto. Nessa direção, Cabral (2016, p. 147) considera o texto "um objeto que apresenta uma estrutura composicional a qual retrata um projeto enunciativo" de quem o elaborou visando a um interlocutor, ou seja, um leitor. Essa perspectiva nos remete à noção de plano de texto, que, de acordo com Marquesi (2014), constitui importante fator unificador da estrutura composicional, por ser "um princípio organizador que permite atender e materializar as intenções de produção e distribuir a informação no desenvolvimento da textualidade" (CABRAL, 2013, p. 246). Vale lembrar que, para Adam (2011, p. 256), “o reconhecimento do texto como um todo passa pela percepção de um plano de texto”, uma vez que texto é um objeto estruturado, seja pelas relações internas, explícitas ou implícitas, entre seus constituintes, 
Linha D'Água (Online), São Paulo, v. 31, n. 1, p. 51-71, jan.-abril 2018

seja porque seu tratamento desencadeia a intervenção de esquemas cognitivos de conhecimento, gerais e específicos, como por exemplo, scripts ou superestruturas textuais, além de opiniões, crenças (CABRAL; MARQUESI, 2015, p. 13).

Dessa perspectiva, assume importante papel para o texto e para a produção escrita o conceito de contexto como construto sociocognitivo (VAN DIJK, 2016), isto é, uma representação mental construída pelo produtor a respeito da situação comunicativa, de suas intenções e do leitor, ou possíveis leitores. Essa representação depende também dos conhecimentos do produtor, uma vez que a construção de um modelo de contexto constitui um processo que envolve a ativação de modelos de situação, os quais constituem representações mentais presentes na memória a respeito de situações vividas, experimentadas, apenas lidas ou, ainda, que foram objeto de observação por parte do produtor. Tais experiências permitem construir na memória representações que ficam acessíveis e são ativadas no momento da produção (CABRAL; MARQUESI, 2015). Essas representações também são reavaliadas, revistas, no processo de escrita, conforme se desenvolve o texto.

Nessa direção, Cabral e Marquesi (2015, p. 15) salientam que

o sentido de um texto não é algo para ser encontrado no texto, mas algo para ser construído na mente do leitor usando o texto, ou, na escrita, construído por meio do texto, a partir do que está na mente do produtor, de acordo com as intenções de cada um.

O verbo construir nos remete a algo que se dá em processo e, como tal, é constantemente reavaliado, repensado, revisado. Da mesma forma, o processo de revisão textual acontece, como postula Pinto (2015), recursivamente, e cumpre importante função na construção dos sentidos do texto. Para essa autora, a escrita deve ser tratada como um processo recursivo assente na revisão, noção que vai ao encontro do que defende Heurley (2006), para quem a revisão diz respeito a um processo de reexame sistemático do texto com vistas a melhorá-lo.

Além disso, podemos afirmar, com base em Pinto (2015, p. 32), que o produtor, ao "selecionar a solução supostamente mais ajustada a uma situação, exerce seu poder de controlee de decisão sobre as incongruências encontradas". Essa reflexão nos remete de volta a Heurley (2006), segundo quem a revisão permite não apenas verificar e melhorar o texto final, mas também supervisionar o processo 
Linha D'Água (Online), São Paulo, v. 31, n. 1, p. 51-71, jan.-abril 2018

de planificação de objetivos do texto e o tratamento dado à elaboração. $\mathrm{O}$ autor destaca que, na revisão, o movimento de escrita é interrompido temporariamente para que se opere uma modificação em alguma parte do texto. Em suma, a revisão permite suprir processos falhos durante a escrita e no fim dela. Por essa razão, o processo de escrita não pode "ser visto como um movimento linear que exclua qualquer movimento recursivo" (PINTO, 2015, p. 30).

Tocamos em três conceitos que consideramos fundamentais para a produção textual: contexto, plano de texto e revisão. Esses conceitos atuam de forma inter -relacionada no processo de escrita, uma vez que estão envolvidos em operações necessárias às quais o produtor ou leitor precisa recorrer para produzir ou ler um texto (COIRRIER; GAONAC'H; PASSERAULT, 1996). Para Cabral (2013), é importante que o produtor adquira consciência desses conceitos e os compreenda como processos que podem auxiliá-lo na escrita, especialmente se os utilizar sabendo como ocorrem. O produtor maduro, segundo a autora, tem essa clareza e os utiliza estrategicamente ao planejar um texto. Mas essa é uma habilidade do produtor maduro, que precisa ser desenvolvida ao longo da aprendizagem.

Kellog (2008) postula que o desenvolvimento das habilidades de escrita se dá em três estágios, a saber: no primeiro estágio, que o pesquisador chama de knowledge-telling, ou nível de narração do conhecimento, o produtor escreve para contar o que sabe. Nesse nível, o produtor não planeja seu texto, limita-se a recuperar as ideias na memória e não realiza muitos procedimentos relacionados à revisão.

O estágio intermediário, denominado knowledge-transforming, ou nível de transformação do conhecimento, caracteriza-se pela interação entre planejar o texto, traduzir o plano em enunciados e revisar. Podemos dizer que, nesse caso, o produtor transforma o que sabe em seu próprio benefício, pois leva em conta seus objetivos. No entanto, limita-se à representação de si próprio, o que é considerado no momento da revisão. Assim, nesse estágio, a interação no processo de escrita envolve apenas o produtor, seus objetivos e o texto.

O estágio avançado, chamado de knowledge-crafting, ou nível de construção do conhecimento, é característico de produtores adultos e profissionais. O produtor do texto, além de ter uma representação do texto que pretende elaborar, tem uma representação de si e constrói uma imagem do leitor; esses três elementos interagem 
Linha D'Água (Online), São Paulo, v. 31, n. 1, p. 51-71, jan.-abril 2018

na produção textual e exercem influência tanto no processo de planificação quanto no processo de revisão.

De acordo com Marquesi, Elias e Cabral (2017), a planificação textual constitui um processo complexo que inclui duas etapas, como pontuam David e Plane (1996). A primeira etapa consiste em recuperar ideias da memória para a escrita; a segunda inclui organizar as ideias recuperadas e imaginar o conhecimento que o leitor já detém para, então, estruturar o texto conforme os objetivos do produtor em relação ao seu leitor. Como Cabral (2013, p. 255) salienta, "a geração de ideias constitui uma ação geral para a produção de um texto; já a planificação de um texto concreto a partir da geração de ideias é própria de produtores maduros e expertos que procuram controlar sua produção”.

Ao articularmos os postulados dos autores citados no parágrafo anterior aos ensinamentos de Kellog (2008), inferimos que somente produtores profissionais realizam plenamente a planificação do texto, levando em conta o leitor que têm em mente para organizar a materialidade textual. Essa organização resulta do trabalho criativo do produtor, que utiliza os conhecimentos recuperados da memória para construir um conhecimento novo que lhe permita atingir os objetivos comunicativos frente a seu leitor, conforme ressaltado no início desta seção.

\section{Resultados de correção de redações do vestibular: critérios e habilidades}

Conforme expusemos no início deste trabalho, o ingresso no ensino universitário depende, em parte, de uma prova escrita, na qual o estudante deve defender um ponto de vista em relação a um tema proposto. A fim de refletirmos sobre esse processo, elegemos como corpus provas do vestibular para o curso de Direito de uma universidade privada do Estado de São Paulo. Desse modo, nesta seção, apresentamos as recomendações aos candidatos, contidas em todas as propostas de redação, e os critérios para avaliação que orientam o trabalho dos corretores e estabelecem os parâmetros de pontuação. Em seguida, expomos resultados obtidos em um conjunto de 50 provas. Esses dados articulam nossas reflexões em torno do que se espera dos estudantes que ingressam no ensino superior e o que eles apresentam em termos produção escrita. 
Linha D'Água (Online), São Paulo, v. 31, n. 1, p. 51-71, jan.-abril 2018

As recomendações que acompanham as propostas de redação são as seguintes:

- Elabore um texto dissertativo-argumentativo;

- Não deixe de basear sua posição em fatos, dados, exemplos;

- Analise, reflita em torno da problemática do tema e argumente;

- Escreva o texto na modalidade padrão da língua portuguesa;

- Não desrespeite os Direitos Humanos;

- Não faça o texto em forma de poema (versos) ou narração;

- Não se esqueça do título.

Essas recomendações especificam os limites do gênero redação de vestibular: o texto deve ser do tipo dissertativo-argumentativo e sua estrutura não pode ser poética ou narrativa, além disso, deve ser contemplado com um título; deve ser elaborado com base em sequências argumentativas, como evidenciado na orientação "Não deixe de basear sua posição em fatos, dados, exemplos". Isso implica que o candidato deve expor uma tese, explicitar uma tomada de posição e se apoiar em dados, ou seja, deve argumentar. Temos aí os componentes da sequência argumentativa de base (ADAM, 2011).

As recomendações explicitam também a necessidade do emprego da "modalidade padrão da língua portuguesa" e, na esteira do que recomenda o Enem, a prova rechaça manifestações que desrespeitem os Direitos Humanos, o que revela uma preocupação social.

Em consonância com as recomendações, os critérios de correção propostos abrangem três dimensões: 1. gênero e tema proposto; 2. articulação discursiva; 3 . recursos linguísticos. A primeira dimensão diz respeito ao gênero, às suas limitações e à manutenção do tema. Esse parâmetro estabelece que o candidato demonstre conhecer o gênero redação de vestibular e suas especificidades e compreenda o tema proposto, mantendo-o no desenvolvimento do texto. Espera-se também que o candidato não reproduza o senso comum e que utilize as informações contidas nos textos motivadores, articulando-as com seus próprios conhecimentos de forma criativa, característica do produtor proficiente, profissional (KELLOG, 2008), conforme expusemos na seção anterior. 
Linha D'Água (Online), São Paulo, v. 31, n. 1, p. 51-71, jan.-abril 2018

A segunda dimensão, relacionada à articulação discursiva, estabelece que o candidato mostre conhecimento da técnica da composição dissertativa. $\mathrm{Na}$ avaliação desse item, o corretor deve verificar se raciocínio do candidato na exposição e defesa de suas ideias se mantém ao longo do texto, o que nos remete à manutenção da coerência textual. Esse critério também avalia a capacidade argumentativa do candidato e se os argumentos são consistentes e convincentes. Uma argumentação composta de argumentos consistentes tem a ver, antes de tudo, com a pertinência dos argumentos em relação ao tema. Além disso, é preciso considerar a estrutura composicional argumentativa que articula os argumentos: dados e fatos devem conduzir a uma conclusão, e não o inverso, que pode invalidar a argumentação.

Por fim, a terceira dimensão, que diz respeito aos recursos linguísticos, tem a ver com o uso da norma padrão da língua portuguesa. Espera-se que o candidato evite o emprego de expressões cristalizadas pelo uso e modismos, procurando ser expressivo. Além disso, deve empregar elementos de coesão adequados, de modo a explicitar as relações entre segmentos da superfície textual.

Os parâmetros constantes nos critérios 1 e 2 evidenciam os conceitos de gênero textual, progressão e manutenção temática, conhecimentos prévios, argumentação e articulação textual. Esses conceitos têm a ver com a coerência textual e remetem tanto ao contexto posto na proposta como o representado mentalmente pelo produtor. Assim, podemos afirmar que estão envolvidos os conceitos de plano de texto e de sequência argumentativa. Os parâmetros referentes ao critério 3 focalizam a revisão, que, evidentemente, retoma os dois itens anteriores.

Considerando os critérios estabelecidos, foram determinadas quatro faixas de notas, a saber:

- não satisfatório - o produtor, na escrita de seu texto, não observa por completo algum ou mais de um dos três critérios estabelecidos;

- fraco - o produtor tangencia o tema ou o gênero; o texto apresenta falhas no desenvolvimento da argumentação e na formulação da tese; apresenta quebras, demonstrando que as ideias não estão bem articuladas, ou repete recursos, indicando falha na progressão, apesar de apresentar elementos de coesão; apresenta deslizes gramaticais ou exige significativa revisão; 
Linha D'Água (Online), São Paulo, v. 31, n. 1, p. 51-71, jan.-abril 2018

- $\quad$ satisfatório - embora o produtor respeite o gênero e a tipologia, não expande a discussão; emprega os recursos linguísticos adequadamente, mas sem explorá-los para efeitos criativos; o texto apresenta alguns deslizes que o comprometem.

- plenamente satisfatório - o produtor, na escrita de seu texto, observa adequadamente todos os critérios estabelecidos.

O levantamento efetuado em 50 provas indicou que nenhum candidato atingiu o nível plenamente satisfatório e apenas 5 ficaram no nível não satisfatório, o que representa $10 \%$ das provas verificadas. Trinta provas ficaram no nível fraco, ou seja, $60 \%$, o que representa a maioria significativa de candidatos considerados fracos; no nível satisfatório foram enquadradas 15 provas, ou 30\% do total de candidatos.

É compreensível que os resultados tenham se concentrado nos níveis fraco e satisfatório, que não correspondem ao nível de escrita experta e profissional tal como postula Kellog (2008); de fato, o nível plenamente satisfatório corresponde ao produtor dotado de expertise. Entretanto, vale verificar, considerando-se esses resultados, quais são as dificuldades a serem superadas pelos ingressantes na Universidade, a fim de propor estratégias para que possam atingir o nível de expertise esperado no contexto profissional.

$\mathrm{Na}$ próxima seção, apresentamos a análise exploratória de uma redação, com o intuito de identificar os elementos que o candidato deixou de contemplar em seu texto e que revelam o nível meramente satisfatório no qual foi classificado. Por meio desse levantamento, elencamos as dificuldades enfrentadas pelo candidato na escrita de seu texto.

\section{Análise exploratória de uma redação de vestibular para o curso de Direito}

Elegemos para análise, o texto que obteve a maior nota no conjunto das 50 provas de redação mencionadas na seção anterior. Cumpre lembrar que, embora seja a redação de maior nota no conjunto, sua pontuação não atingiu o nível plenamente satisfatório, o que nos permite identificar elementos não contemplados tanto no que diz respeito às instruções da proposta quanto no que diz respeito aos critérios 
Linha D'Água (Online), São Paulo, v. 31, n. 1, p. 51-71, jan.-abril 2018

de correção. Esses elementos indicam os itens que devem ser explorados ao longo do percurso do estudante na Universidade.

Conforme expusemos na seção anterior, três das recomendações da proposta articulam-se ao critério gênero e tema proposto: "Elabore um texto dissertativo-argumentativo"; "Não faça o texto em forma de poema (versos) ou narração"; "Não se esqueça do título". Podemos afirmar que a redação em análise atende em parte as três recomendações. Trata-se de um texto dissertativo, não está escrito na forma de poema nem é uma narração e apresenta um título, embora se mostre vago e não reflita o conteúdo do texto.-

O critério que se articula com essas recomendações amplia a avaliação para a questão da temática do texto, estabelecendo que o candidato demonstre compreensão do tema "A educação é a única solução" e mantenha-se fiel a ele. O critério estabelece, ainda, que o candidato não deve reproduzir o senso comum e deve mostrar que abstraiu ideias pertinentes dos elementos fornecidos na proposta.

Para motivar a reflexão dos candidatos, a proposta apresenta dois enunciados de personalidades famosas (Paulo Freire e Malala Yousafzai) e um quadro que ilustra a evolução intelectual por meio do estudo, representado por um livro. Em uma figura que estabelece analogia com o quadro ilustrativo da evolução humana, o quadrinho mostra uma criança sentada ao chão; à medida que lê, cresce e se torna adulto, vestido de terno, símbolo de estatuto social elevado e de inclusão no setor produtivo intelectual da sociedade.

Embora os dois enunciados motivadores sejam breves, de uma linha e meia cada um, pode-se, com base neles e articulando-os ao quadrinho, construir uma reflexão em torno da importância do estudo tanto para o sucesso individual quanto para o progresso da nação. Podemos afirmar que os dois enunciados constituem teses a serem defendidas pelo candidato.

O produtor do texto em análise optou por abordar a importância da educação para o progresso da nação. Ele demonstra, portanto, compreensão da temática e elabora ideias pertinentes ao tema com base nos textos fornecidos. Além disso, utiliza o enunciado de Paulo Freire para introduzir seu texto; mantém-se fiel ao tema, sem desvios gritantes. Assim, podemos concluir que, do ponto de vista do critério gênero e tema proposto, o candidato atende o esperado. 
Linha D'Água (Online), São Paulo, v. 31, n. 1, p. 51-71, jan.-abril 2018

Três das recomendações aos candidatos relacionam-se com o critério articulação discursiva: "Não deixe de basear sua posição em fatos, dados, exemplos"; "Analise, reflita em torno da problemática do tema e argumente"; "Não desrespeite os Direitos Humanos". O critério amplia a questão ao estabelecer que o candidato deve demonstrar conhecimento da técnica de composição dissertativa, o que implica raciocínio e defesa de ideias; as conclusões devem decorrer da argumentação, que precisa ser convincente e composta por argumentos consistentes. Além disso, o texto deve apresentar unidade. No texto analisado, observamos que o candidato não fere os direitos humanos ao expor suas ideias e demonstra reflexão baseada nos textos motivadores, inclusive, utiliza um deles em sua produção, articulando-o às ideias que expõe.

A proposta recomenda que o candidato apresente fatos e dados para fundamentar sua argumentação, de modo a torná-la convincente. Considerando que os textos motivadores apresentavam as teses a serem defendidas e que cada um tinha a extensão de uma linha e meia, podemos afirmar que eles não forneceram os dados e fatos que poderiam servir para a argumentação consistente que tivesse poder de convencimento, conforme preconizado nas recomendações e nos critérios de correção. Dessa forma, o candidato contou apenas com seus conhecimentos, o que resultou em uma argumentação fraca, carente de elementos.

$\mathrm{O}$ candidato tentou apresentar fatos que sustentassem sua tese, assim, por exemplo, fez referência a dados estatísticos: "os dados estatísticos comprovam uma transformação da sociedade o seu estado de evolução ao longo dos anos, a partir da importância dada a educação". Embora mencione a existência de dados estatísticos, não os apresenta, o que invalida esse dado como argumento para sustentar a tese.

Em seguida, ainda, na tentativa de apoiar sua tese, afirma que "A educação nesses países é ponto chave. Desde criança, o investimento, seja dos pais ou do próprio governo, é levado a sério". Tal fato apoia a tese de que a educação sempre será o percurso para a mudança social. Entretanto, faltam dados; o candidato não explicita os países que investem na educação nem quanto investem ou quais resultados obtêm. Como faltam dados concretos, a argumentação permanece vaga e atrelada a generalidades, o que a enfraquece. 
Linha D'Água (Online), São Paulo, v. 31, n. 1, p. 51-71, jan.-abril 2018

A proposta do candidato é igualmente vaga e genérica. Ele afirma em seu texto que "o que os países subdesenvolvidos necessitam para uma transformação clara e duradoura, seria o foco em política e suas controvérsias, a economia e suas brigas de interesses, e voltar ao ponto de partida chamado educação". Tal afirmação retoma a tese inicial, que já continha uma proposta, mas não expõe "como" realizá-la, assim, faltam dados que apoiem essa tese.

$\mathrm{O}$ candidato termina seu texto com uma sugestão de ação, a qual constitui um dado que sustenta a tese contida na proposta: "A começar no investimento à educação infantil e juvenil, chegando à universidade, preparando o caminho da sociedade para uma transformação de mentalidades". Embora o dado seja um elemento pertinente à estrutura argumentativa canônica, correspondendo às recomendações do critério, não podemos afirmar que o candidato tenha atendido ao esperado, pois o dado é impreciso, uma vez que não especifica como seriam empregados os investimentos sugeridos.

No que se refere ao critério recursos linguísticos, apenas uma recomendação se articula a ele de forma clara na proposta: "Escreva o texto na modalidade padrão da língua portuguesa”. Esse critério determina que seja observado se o candidato se vale de "todos os recursos linguísticos para transmitir sua mensagem", demonstrando saber utilizar adequadamente os elementos coesivos. Não devem ser utilizadas expressões cristalizadas pelo uso, modismos e artificialismos. $\mathrm{O}$ texto deve apresentar correção gramatical e expressividade. Evidentemente, expressividade, elementos coesivos, organização textual são fenômenos também pertinentes e fundamentais ao cumprimento dos demais critérios. Conforme indicado pelo corretor, o texto apresenta inadequações de concordância, pontuação e uso inapropriado de marcadores. Identificamos, ainda, mau uso do pronome relativo e pequenos deslizes de paralelismo. Apesar dessas imperfeições, pode-se dizer que o texto atende satisfatoriamente à modalidade padrão da língua, conforme recomendado na proposta.

Relativamente aos recursos coesivos, a cada início de parágrafo, o candidato apresenta uma expressão que, de alguma forma, retoma o parágrafo anterior e projeta o próximo: "para comprovar esse fato"; "dado esse fato". A retomada referencial de um parágrafo a outro, reforçada por um mesmo item lexical, revela a preocupação de sinalizar a manutenção temática por meio de um recurso linguístico. 
Linha D'Água (Online), São Paulo, v. 31, n. 1, p. 51-71, jan.-abril 2018

Assim, por exemplo, o primeiro parágrafo termina com a palavra "comportamento", retomada na primeira linha do parágrafo seguinte: "é possível uma transformação de comportamentos". Da mesma forma, as expressões introdutórias dos dois parágrafos seguintes apresentam elementos de retomada referencial, não mais pelo mesmo item lexical, mas por anáforas resumidoras, que retomam não uma palavra do parágrafo anterior, mas um enunciado completo: "esse fato". Podemos afirmar, com base nessas breves observações, que o candidato utiliza adequadamente os recursos de coesão, articulando seu texto e conferindo-lhe unidade.

O critério recursos linguísticos preconiza que o candidato deve evitar expressões cristalizadas pelo uso, modismos e artificialismos, o que nos remete ao critério gênero e tema propostos, no qual se estabelece que o texto não deve reproduzir o senso comum. Apenas para exemplificar, destacamos o enunciado final do texto, que ilustra o emprego de uma expressão bastante desgastada e o apelo ao senso comum: "preparando o caminho da sociedade para uma transformação de mentalidades". O senso comum enfraquece a argumentação, pois ao utilizá-lo, o candidato demonstra não deter elementos sólidos para sustentar sua argumentação, o que a torna artificial e pouco convincente.

As breves observações elencadas indicam que as dificuldades de escrita do candidato dizem respeito especialmente à articulação discursiva, sobretudo, no que se refere à argumentação. Essa questão nos remete aos três conceitos abordados na primeira seção deste trabalho: plano de texto, contexto e revisão.

A análise do texto selecionado permite-nos construir um plano de texto, cujo desenvolvimento se dá em três blocos, a saber:

\section{BLOCO 1}

Introdução do tema por meio de retomada de texto motivador + apresentação da tese

A frase do pensador Paulo Freire: "Se a educação sozinha não transforma a sociedade, sem ela tampouco a sociedade muda" resume a sociedade desde o seu surgimento no quesito comportamento.

Tese - a educação sempre será o percursor dessa mudança. 
Linha D'Água (Online), São Paulo, v. 31, n. 1, p. 51-71, jan.-abril 2018

\section{BLOCO 2}

Estabelecimento de relação com o bloco anterior - por meio de anáfora resumidora de caráter vago - Para comprovar esse fato

Proposta de argumento baseado na comparação - países desenvolvidos X países subdesenvolvidos - destaque para os países desenvolvidos - investimento em educação. Referência a dados estatísticos sem comprovação-dados estatísticos comprovam.

\section{BLOCO 3}

Estabelecimento de relação com o bloco anterior - por meio de anáfora resumidora de caráter vago - Dado esse fato,

Proposta de atuação baseada na tese - o que os países subdesenvolvidos necessitam para uma transformação clara e duradoura (...) voltar ao ponto de partida chamado educação. Fechamento do texto com enunciado fundado no senso comum - preparando o caminho da sociedade para uma transformação de mentalidades.

O levantamento do plano do texto possibilita-nos observar que, embora o produtor tenha demonstrado preocupação de remeter cada bloco ao bloco anterior, por meio de uma estratégia de retomada referencial, os três blocos não se articulam entre si. Na verdade, o que corre é a justaposição de ideias; apresenta-se uma tese, em seguida, expõe-se um argumento frágil, porque não comprovado por dados concretos; propõe-se uma ação vaga e genérica e encerra-se com um enunciado do senso comum. O texto parece, assim, pouco dinâmico. Como resultado desse processo, o produtor não propõe um contexto claro para a problemática tratada em seu texto.

$\mathrm{O}$ candidato menciona, por exemplo, países desenvolvidos e subdesenvolvidos, mas não lhes atribui nome. O leitor atento pode inferir que o candidato ensaia uma referência ao Brasil, quando menciona "mudar o foco em política e suas controvérsias, a economia e suas brigas de interesses", mas, de modo geral, não é possível construir uma representação mental clara do contexto imaginado pelo produtor para a problemática tratada em seu texto.

Finalmente, notamos que o candidato falhou no processo de revisão, pois, em seu movimento de escrita, muitos deslizes relativos a escolhas linguísticas comprometeram o texto. Também fica claro que o candidato não seguiu um planejamento textual. Podemos inferir que ele não aproveitou o processo de escrita para 
Linha D'Água (Online), São Paulo, v. 31, n. 1, p. 51-71, jan.-abril 2018

supervisionar a planificação em função de seus objetivos ou do tratamento dado à elaboração em curso.

É importante lembrar que, conforme expusemos na primeira seção deste artigo, é própria do produtor maduro a habilidade de utilizar estrategicamente os conceitos aqui abordados, ou seja, o plano de texto, o contexto e a revisão textual, aliando-os ao planejamento do texto. $\mathrm{O}$ candidato que presta exame vestibular não é um produtor maduro, não no sentido proposto por Kellog (2008). Se o estudante chega à universidade ainda precisando desenvolver habilidades de escrita, cabe a ela lhe dar condições para que as desenvolva e se torne proficiente, de modo a ser bem-sucedido futuramente em contextos profissionais.

\section{Reflexões sobre o desenvolvimento das habilidades de escrita na universidade}

A proficiência em escrita, segundo Kellog e Whiteford (2012), diz respeito à capacidade de produzir textos de determinado gênero. Conforme defendem Cabral e Guaranha (2016), cada área de atuação profissional, ou área de conhecimento, contempla inúmeros conteúdos, os quais fazem variar os saberes retóricos e discursivos. Nessa direção, cabe à universidade oferecer as condições para que os estudantes-apropriemse dos diferentes gêneros e discursos que circulam na área de atuação profissional para a qual determinado curso conduz (CABRAL; GUARANHA, 2016).

Com base nos postulados aqui estudados e considerando a análise realizada, propomos que sejam utilizados, ao longo do curso de Direito, tanto para a escrita, quanto para a leitura, gêneros textuais da área jurídica, como petições, contratos, sentenças judiciais e artigos científicos. Essa estratégia para além do caráter social e prático a que faz referência Koch (1997) quando define texto, permite que os alunos se familiarizem com os usos linguísticos da área profissional em que vão atuar. Assim, sedimenta-se o saber linguístico fundado em conteúdos próprios de uma área específica, o que possibilita aos estudantes construírem conhecimentos que possam ser ativados no momento da escrita.

Entendemos que a utilização de gêneros textuais específicos da área em que atuará permite que o estudante construa conhecimentos relacionados e armazene 
Linha D'Água (Online), São Paulo, v. 31, n. 1, p. 51-71, jan.-abril 2018

na memória representações a respeito de como são os textos que terá de produzir como profissional.

Essas representações dizem respeito tanto à estrutura composicional quanto à função de cada gênero. $\mathrm{O}$ contato com textos típicos da área em que atuará também permite que o aluno construa representações de como são os profissionais com os quais interagirá. Esse conhecimento lhe possibilita perceber, paulatinamente, que os textos serão dirigidos a seus pares. Dessa forma, poderá se tornar mais consciente da importância de se levar em conta, no momento da produção, um possível leitor. Essas representações, futuramente, terão parte na sua proficiência escrita, mais especificamente, na planificação textual. Como destaca Kellog (2008), o produtor maduro elabora uma representação de seu leitor e essa representação exerce influência sobre as produções textuais que realiza.

A análise realizada na seção anterior nos permite afirmar que os jovens ingressantes na universidade produzem textos cujos planos indicam que seus projetos enunciativos precisam ser mais bem desenvolvidos. As reflexões que desenvolvemos relacionam-se à necessidade de fazer o estudante perceber a importância de ter um plano de texto claro que baseie a escrita e oriente a leitura na direção dos sentidos desejados por ele, produtor, como destaca Cabral (2013). Tal plano, segundo essa autora, é fruto de um plano enunciativo e colaborativo que envolve a compreensão do leitor.

A importância de o produtor levar em conta seu leitor nos remete a duas questões relevantes que visam ao aprimoramento das habilidades de escrita. A primeira delas diz respeito à relação necessária com a leitura. Defendemos que o desenvolvimento do domínio da escrita na universidade está intimamente ligado ao desenvolvimento da leitura, uma vez que esta amplia os conhecimentos do produtor.

A segunda diz respeito à elaboração de planos de texto prévios no processo de planificação. Lembramos, com base em Cabral (2013), que pesquisas têm evidenciado os efeitos positivos da elaboração de planos de escrita. Essa elaboração permite ao estudante tomar consciência de quem é seu leitor e lhe fornece os elementos para a construção de uma representação mental do contexto da escrita, representação essa que pode ser transferida ao texto, possibilitando a construção efetiva de um contexto a ser explicitado no texto por meio de marcas linguísticas. A elaboração de planos e 
Linha D'Água (Online), São Paulo, v. 31, n. 1, p. 51-71, jan.-abril 2018

a construção de representações e de modelos de situação que fundamentarão a elaboração do texto, assim compreendidas, constituem elementos da produção textual que podem passar por reavaliações e reformulações durante o processo de escrita, conduzindo também a uma reformulação do plano textual.

O processo de retomada recursiva nos remete ao conceito de revisão, considerada por Heurley (2006) um processo sistemático de reexame de um texto com vistas a melhorá-lo. Essa definição evidencia a importância da revisão para o resultado de uma produção escrita e toca em questões que necessitam de reflexão. A nosso ver, o produtor atento à revisão nutre preocupação com seu leitor e se esforça para tornar o texto mais compreensível.

No entanto, é importante não perdermos de vista que o processo de revisão assim compreendido requer um produtor que detenha os conhecimentos de mundo, linguísticos e textuais, necessários para a revisão de forma adequada.

Assim, propomos, para o ensino na área jurídica, desde o primeiro ano na Universidade, o trabalho de conscientização dos processos de planificação, elaboração e revisão, por meio de leitura e discussão do próprio texto do aluno, a começar pela redação elaborada no vestibular. Desse modo, entendemos ser possível explorar os conceitos que consideramos aliados aos conhecimentos de língua necessários à concretização da tessitura textual.

\section{Conclusão}

Ao iniciarmos este texto, propusemos duas perguntas e, para respondê-las estabelecemos quatro objetivos. No cumprimento desses objetivos, abordamos os conceitos de plano de texto, de contexto e de revisão da escrita. Esses conceitos orientaram nossas reflexões em torno de critérios estabelecidos por uma universidade da cidade de São Paulo para a correção de redações do exame vestibular; relacionamos tais critérios a resultados obtidos em 50 redações do vestibular para o curso de Direito.

De modo a desenvolvermos as reflexões que apresentamos nas seções anteriores, selecionamos a redação que obteve a maior nota. Notamos que esse texto, mesmo sendo o melhor do grupo de 50, revelou dificuldades do candidato na realização da tarefa de escrita. 
Linha D'Água (Online), São Paulo, v. 31, n. 1, p. 51-71, jan.-abril 2018

$\mathrm{Na}$ análise que empreendemos, consideramos os critérios estabelecidos para a correção da redação e os articulamos aos fundamentos teóricos propostos no início deste artigo. $\mathrm{O}$ estabelecimento dessa relação nos permitiu responder à primeira pergunta que propusemos neste estudo.

Os resultados obtidos por meio da análise da redação nos forneceram dados concretos relativos às dificuldades de escrita dos estudantes que ingressam na universidade. Com base nesses dados, apresentamos algumas reflexões que, acreditamos, responderam à segunda pergunta.

As respostas às questões aqui definidas, certamente, abrem perspectivas para novas investigações e horizontes para o enfrentamento dos desafios da escrita na universidade. Busquemos, assim, a definição de novas perguntas que orientem nossos estudos, cumprindo o processo contínuo e continuado deste importante trabalho na formação acadêmica.

\section{Referências}

ADAM, Jean-Michel. A Linguística Textual: introdução à análise textual dos discursos. Trad. Maria das Graças Soares Rodrigues, João Gomes da Silva Neto, Luis Passeggi, Eulália Vera Lúcia Fraga Leurquin. São Paulo: Cortez, 2011.

CABRAL, Ana Lúcia Tinoco. Texto e argumentação nas redes sociais: planos de texto, sequências textuais e estratégias linguísticas. In: FERREIRA, Fernando Aparecido; LUDOVICE, Camila de Araújo Beraldo; PERNAMBUCO, Juscelino. O texto: processos, práticas, abordagens teóricas. Franca: Unifran, 2016.

.Ensino de língua portuguesa para a formação profissional na universidade: as sequências narrativas e argumentativas no gênero petição inicial. Revista Linha d'Água,v. 28, n. 2, p.122-136, 2015. Disponível em: <http://www.revistas.usp.br/linhadagua/article/view/106526/106256>. Acesso em: 6 out. 2017.

O conceito de plano de texto: contribuições para o planejamento da produção escrita. Revista Linha d'Água, v. 26, n. 2, p. 241-259, 2013. Disponível em: <http://www.revistas.usp.br/ linhadagua/index>. Acesso em: 6 out. 2017.

MARQUESI, S. C., CABRAL, A. L. T. A escrita na universidade: dificuldades na redação do 
Linha D'Água (Online), São Paulo, v. 31, n. 1, p. 51-71, jan.-abril 2018

CABRAL, Ana Lúcia Tinoco; GUARANHA, Manoel Francisco. Escolhas linguísticas e argumentação: reflexões sobre produção textual para estudantes de direito. Revista Diadorim, v. 2, n. 18, p. 168-185, 2016. Disponível em: <http://www.revistadiadorim.letras.ufrj.br/index.php/ revistadiadorim/announcement/view/10>. Acesso em: 6 out. 2017.

CABRAL, Ana Lúcia Tinoco; MARQUESI, Sueli Cristina. Escrita e leitura em diálogo com as tecnologias da informação. In: CABRAL, Ana Lúcia Tinoco; MINEL, Jean-Luc; MARQUESI, Sueli Cristina. (Org.) Leitura, escrita e tecnologias da informação. São Paulo: Terracota, 2015.

COIRIER, Pierre; GAONAC'H, Daniel; PASSERAULT, Jean-Michel. Psycholinguistique textuelle - une approche cognitive de la compréhension et de la production des texts. Paris: Armand Colin, 1996.

DAVID, Jacques; PLANE, Sylvie. L'apprentissage de l'écriture de l'école au collège. Paris: PUF, 1996.

HEURLEY, Laurent. La révision de texte: l'approche de Psycologie Cognitive. In: PÉTILLON, Sabine; GARNIER, Franck. La révision de texte: méthodes, outils et processus. Langage, 164, Paris, Larousse, 2006.

KELLOGG, Ronald. T. Training writing skills: a cognitive developmental perspective. Journal of Writing Research, 1(1), 2008, p. 1-26.

KELLOGG, Ronald; WHITEFORD, Alison. The Development of writing expertise. In: GRIGORENKO, Elena; MAMBRINO, Elisa; PREISS, David (Eds.) Writing: a mosaic of new perspectives. New York/London: Psychology Press/Taylor \& Francis Group, 2012.

KOCH, Ingedore Villaça. A inter-ação pela linguagem. São Paulo: Contexto, 1997.

MARQUESI, Sueli Cristina. Sequências textuais descritivas e suas funções nas sentenças judiciais. In: PINTO, Rosalice; CABRAL, Ana Lúcia Tinoco; RODRIGUES, Maria das Graças Soares. Linguagem e direito: perspectivas teóricas e práticas. São Paulo: Contexto, 2016. v.1.

Planos e sequências textuais em sentenças judiciais de processo-crime. In: DIOS, Angel Marcos de. (Ed.) La Lengua Portuguesa - Estudios sobre literatura y cultura de expresión portuguesa. Salamanca: Ediciones Universidad de Salamanca, 2014. v. 1. 
Linha D'Água (Online), São Paulo, v. 31, n. 1, p. 51-71, jan.-abril 2018

MARQUESI, Sueli Cristina; ELIAS, Vanda Maria; CABRAL, Ana Lúcia Tinoco. Planos de texto, sequências textuais e orientação argumentativa. In: MARQUESI, Sueli Cristina; PAULIUKONIS, Aparecida Lino; ELIAS, Vanda Maria. Linguística textual e ensino. São Paulo: Contexto, 2017.

MARQUESI, Sueli Cristina; RODRIGUES, Maria das Graças Soares; CABRAL, Ana Lúcia Tinoco. Sequências textuais descritivas e responsabilidade enunciativa: a orientação argumentativa em sentença judicial condenatória. In: ANDRADE, Carlos Augusto Baptista de; MICHELETTI, Guaraciaba; SEARA, Isabel Roboredo. (Org.) Memória, discurso e tecnologia. São Paulo: Terracota, 2016.

PINTO, Maria da Graça Lisboa de Castro. A escrita e seus horizontes: teoria e prática. São Paulo: Terracota, 2015.

VAN DIJK, Teun A. Discurso-cognição-sociedade: estado atual e perspectivas da abordagem sociocognitiva do discurso. Trad. Pedro Theobald. Revista Letrônica, Porto Alegre, v. 9, n. esp. (supl.), s8-s29, p. 6-29, nov. 2016. Disponível em: <http://revistaseletronicas.pucrs.br/ojs/index. php/letronica/> Acesso em: 4 out. 2017.

. Discurso e contexto: uma abordagem sociocognitiva. Trad. Rodolfo Ilari. São Paulo: Contexto, 2012.

Recebido em 11/01/2018.

Aprovado em 20/02/2018. 
Linha D'Água (Online), São Paulo, v. 31, n. 1, p. 51-71, jan.-abril 2018

\section{Anexo}

\section{Prepranardo o caminho}

A hase do pensadon Paulo Freine: "Ie a educacialo rogishar naco trans forma ca socirdade, sern ela tampouco a jociedade muda" reseme la sociedade dexde o seu surgimento ino quesitic comportamentos.

E' posiviel una trans formacáo el compotancintes através da religiá, da poléteca, da economia, entre eitros aspectos. Mas va edveacáo sempre será os perauson 1 dessa mudanca. Para comiprovar esse foto, hasta analisar as difirencon que ditam um país convo dexnvolvido e um como subdenud vido. Os dados estatistices comprovam una trons formacáo da sociedade on os seu estado de elolucáo as l'ongo dos anos, a hantin da importancia dada' a educiacóo fonde se destaca os raúses desenvolvidos. A educaciato nesses taises $x$ ponto drave. Des de onianca, o investimento, lisa dos pais ou do pró́pio governo \& livado a sério do anteride que se aplica ate as estrutiras de excolas e unirersidades, sendo referencias mundrais.

Dado esse fate, or que os paires subdensenvolvicess neas. sitam para ema trarrsformacáo clara ediradoura, seria mudar o foos em pólítica e suas controverisias, a ecomomia e suas briags de interesses, e voltas av ponto de partida dramado educacáo. A comecar no imestimento ia educavóo infantil í jurenil, chegando in universidadus, préparando o caminho da sociedarde para una transformaciáo de mentalidades. Coneondoncra - Vhantraras: mareadora

NÃO USE O VERSO 